Tropical Journal of Pharmaceutical Research September 2014; 13 (9): 1487-1493

ISSN: $1596-5996$ (print); 1596-9827 (electronic)

(c) Pharmacotherapy Group, Faculty of Pharmacy, University of Benin, Benin City, 300001 Nigeria.

All rights reserved.

Available online at http://www.tjpr.org

Original Research Article

http://dx.doi.org/10.4314/tjpr.v13i9.15

\title{
Antioxidant Capacity, Radical Scavenging Kinetics and Phenolic Profile of Methanol Extracts of Wild Plants of Southern Sonora, Mexico
}

\author{
EF Moran-Palacio ${ }^{1}$, LA Zamora-Álvarez ${ }^{1}$, NA Stephens-Camacho ${ }^{2}$, GA Yáñez- \\ Farías ${ }^{1}$, A Virgen-Ortiz ${ }^{1}$, O Martínez-Cruz ${ }^{3}$ and JA Rosas-Rodríguez ${ }^{1 *}$ \\ ${ }^{1}$ Departamento de Ciencias Químico Biológicas y Agropecuarias, Universidad de Sonora Unidad Regional Sur. Navojoa, \\ Sonora, Apartado Postal 85390, ${ }^{2}$ Departamento de Nutrición Humana. Universidad Estatal de Sonora Unidad Académica \\ Navojoa. Navojoa, Sonora, ${ }^{3}$ Departamento de Investigación y Posgrado en Alimentos, Universidad de Sonora. Blvd. Luis \\ Encinas y Rosales s/n Col. Centro, Apartado Postal 1658, C.P. 83000, Hermosillo, Sonora, Mexico
}

*For correspondence: Email: jrosas@navojoa.uson.mx; Tel: 01(642)4259950 Ext 7057, 01(642)4259952 Ext 7057

Received: 3 December 2013

Revised accepted: 16 August 2014

\begin{abstract}
Purpose: To investigate the antioxidant and phenolic profiles of methanol extracts from Rhizophora mangle L, Krameria erecta, Lycium berlandieri Dunal, Vallesia glabra Link and Forchammeria watsonii Rose.

Methods: The free radical 2, 2-diphenyl-1-picrylhydrazyl (DPPH) method was used for antioxidant assay of methanol plant extracts. Phenolic compounds determination was carried out by high performance liquid cromatography (HPLC) using an analytical C18 column eluting with acetonitrile on a gradient program.

Results: Extract from Rhizophora mangle $L$ and Krameria erecta displayed 5-fold higher antioxidant capacity than ascorbic acid with DPPH reduction values of 95.71 and $91 \%$, respectively. Anti-radical kinetic analysis and stoichiometric constant values suggest that the compounds responsible for antioxidant activity are polyphenols and flavonoids with a free or mono-substituted catechol group. Ferulic and vanillic acids had higher contents in Rhizophora mangle $L$ (688.45 \pm 18.21 and $7.13 \pm 0.125$ $\mathrm{mg} / \mathrm{g}$, respectively) and Krameria erecta (619.92 $\pm 28.16 \mathrm{mg} / \mathrm{g}$ and $22.29 \pm 0.72 \mathrm{mg} / \mathrm{g}$, respectively) than the other constituents.

Conclusion: Rhizophora mangle and Krameria erecta possess five times the antioxidant activity of ascorbic acid and also demonstrate high phenolic contents, which supports the beneficial properties attributed to these plants in traditional medicine, and also justifies the use of the plants as alternative medicines.
\end{abstract}

Keywords: Rhizophora mangle, Krameria erecta, Ferulic acid, vanillic acid, Antioxidant capacity, Alternative medicines, Phenolics, Anti-radical kinetics

Tropical Journal of Pharmaceutical Research is indexed by Science Citation Index (SciSearch), Scopus, International Pharmaceutical Abstract, Chemical Abstracts, Embase, Index Copernicus, EBSCO, African Index Medicus, JournalSeek, Journal Citation Reports/Science Edition, Directory of Open Access Journals (DOAJ), African Journal Online, Bioline International, Open-J-Gate and Pharmacy Abstracts

\section{INTRODUCTION}

Plants produce a wide variety of antioxidant compounds during their development as a result of unfavorable environmental exposure or mechanical processes, which are capable of counteracting the negative effects of oxidative damage [1]. Antioxidants are used in traditional medicine to improve the human health [2]. The extension on medicinal plant use in Mexico has raised the importance of knowing the compounds responsible of their therapeutic properties [3]. 
More than two hundred plant species that exists in Sonora are used for various purposes in traditional medicine. Previous results in our laboratory demonstrated that Sonora plants as Forchammeria watsonii, Rhizophora mangle and Lycium berlandieri possess antifungal activity against Aspergillus niger and Aspergillus flavus, as well as antibacterial activity against Staphylococcus aureus and Streptococcus pyogenes [Unpublished results].

One of the main problems working with plant extracts is the large compound variation in plant homogenate, which produce a background that inhibits the screening of specific compounds. Some studies proposed exponential decay equations for kinetic analysis of citric juice allowing antioxidant compounds identification [4]. Identification of antioxidant mechanism using kinetic equations is a powerful tool to identify the nature of bioactive compounds. Thus, the present work focuses on the analysis and identification of antioxidant activity of different methanol extracts of medicinal plants from Southern Sonora, Mexico in order to understand the basis of the medicinal use of these plants in this region.

\section{EXPERIMENTAL}

\section{Plant materials}

All plant materials were collected in the southern region of the state of Sonora, Mexico, during February 2011. Professor José Jesús Sánchez Escalante at the Universidad de Sonora Herbarium authenticated the plant samples and voucher specimens were preserved in the laboratory for future reference. The samples consisted of barks of Rhizophora mangle $\mathrm{L}$ (voucher No. 20392; location: 26 42' 10.47" N, $109^{\circ} 31^{\prime} 31.25^{\prime \prime}$ W), Krameria erecta (voucher No. 20391; location: $26^{\circ} 39^{\prime} 50.68^{\prime \prime}$ N, $109^{\circ} 19^{\prime}$ 7.14" W) and Forchammeria watsonii Rose (voucher No. 20393; location: $26^{\circ} 47^{\prime} 37.07^{\prime \prime} \mathrm{N}$, $\left.109^{\circ} 21^{\prime} 7.25^{\prime \prime} \mathrm{W}\right)$, leaf of Vallesia glabra Link (voucher No. 20390; location: $26^{\circ} 53^{\prime} 56.65^{\prime \prime} \mathrm{N}$, location: $109^{\circ} 37^{\prime} 56.17^{\prime \prime} \mathrm{W}$ ) and roots of Lycium berlandieri Dunal (voucher No. 20388; location: $\left.26^{\circ} 53^{\prime} 56.65^{\prime \prime} \mathrm{N}, 109^{\circ} 37^{\prime} 56.17^{\prime \prime} \mathrm{W}\right)$.

\section{Preparation of extracts}

All plants samples were dried at $25^{\circ} \mathrm{C}$ and powdered using an electric mill (Thomas Scientific 3383-L10). The sample was mixed with methanol $(10 \% \mathrm{w} / \mathrm{v})$ and stirred for $96 \mathrm{~h}$ at 25 ${ }^{\circ} \mathrm{C}$. Methanolic extract was concentrated at 40-
$48{ }^{\circ} \mathrm{C}$ and $30 \mathrm{rpm}$ using a rotary evaporator (Yamato RE 300).

\section{Determination of antioxidant capacity}

Antioxidant capacity of methanolic extract was analyzed using the 2, 2-diphenyl-1-picrylhydrazyl (DPPH) method [5]. The reduction of the DPPH radical absorbance was followed at $517 \mathrm{~nm}$ (UV/Vis PerkinElmer LAMBDA 25). Distinct methanolic extract concentration of each plant was evaluated (3.25 - $100 \mu \mathrm{g} / \mathrm{mL})$ in triplicate, and ascorbic acid was used as control. The results were expressed as a percent of $\mathrm{DPPH}$ scavenging.

\section{Antioxidant activity kinetics}

Antioxidant activity kinetics was evaluated by employing exponential decay equations to describe the fast/low antioxidant kinetics and coordinate with the compounds responsible of anti-radical activity [4]. The stoichiometric constant was obtained from the slope of the DPPH reduction and methanolic extract concentration plots. The stoichiometric constant values were correlated with those obtained from pure antioxidant compounds in order to clarify the bioactive compounds present in plant methanolic extracts [6]. Stoichiometric constant was used for anti-radical activity determination contrasted with the control (ascorbic acid). A calibration curve with DPPH was assayed to calculate the molar extinction coefficient. Software Origin 8.0 (OriginLab, Northampton, MA) was used for data fitting and kinetic analysis.

\section{Phytochemical screening}

Phytochemical screening of plant extracts was performed using $1 \mathrm{mg}$ of each plant sample. Meyer and Dragendorff reagents were used for alkaloids detection. Polyphenols were detected by the iron chloride test. Presence of terpenes was evaluated by the Salkowski test. Baljet reagent was used for sesquiterpene lactones presence. Gelatin-tannin reaction was used for those samples polyphenol positive. Flavonoids were identified by the $\mathrm{H}_{2} \mathrm{SO}_{4}$ and Shinoda test. Finally, Liebermann-Burchard test was applied for sterols determination [7].

\section{Determination of phenolic compounds}

Determination of phenolic compounds was carried out using an HPLC Perkin Elmer series 200 system equipped with LC pump, UV/Vis detector and Vacuum Degasser. Chromatographic analysis was performed using 
an analytical scale C18 column, $150 \mathrm{~mm} \times 4.6$ $\mathrm{mm}$. Mobile phase A consisted of $0.1 \%$ trifluoroacetic acid (TFA) in water, and mobile phase B $100 \%$ acetonitrile on a gradient program of $A: B=90: 10$ for $0-0.1$ min, $A: B=$ $90: 10$ for $0.1-50 \mathrm{~min}, A: B=60: 40$ for $50-60 \mathrm{~min}$ and $A: B=55: 45$ at $1.0 \mathrm{~mL} / \mathrm{min}$. The injection volume for methanol extracts and standards was $20 \mu \mathrm{L}$, and absorbance was set up at $280 \mathrm{~nm}$ [8]. The standards used for phenolic compounds profile in plant methanolic extracts consisted on gallic acid, caffeic acid, ferulic acid, vanillic acid, protocatechuic acid, chlorogenic acid and benzoic acid.

\section{Statistical analysis}

All measurements were performed in triplicate for each assay, and the results were expressed as the mean \pm standard deviation. Data were analyzed by one-way analysis of variation (ANOVA) procedures, and differences among means were compared using Tukey and Fisher test with a level of significance of $p<0.05$. The data were analyzed using Software Origin 8.0 (OriginLab, Northampton, MA) for Windows.

\section{RESULTS}

\section{Antioxidant capacity}

The antioxidant capacity of methanolic extract of all plants was concentration dependent displaying a maximal antioxidant capacity at 100 $\mu \mathrm{g} / \mathrm{mL}$. Contrasting with the positive control ascorbic acid $(100 \%)$ the antioxidant capacity of R. mangle $(95.71 \%)$ showed the most elevated DPPH scavenging capacity, followed by $K$. erecta $(91 \%)$, L. berlandieri $(85.99 \%)$ and $V$. glabra $(57.70 \%)$. F. watsonii gave the lowest value of DPPH scavenging (15.23\%). All antioxidant capacity values were statistically different $(p \leq 0.05)$.

\section{Antioxidant activity kinetics}

The molar extinction coefficient of $1.26 \times 10^{-4}$ $\mathrm{Lmol}^{-1} \mathrm{~cm}^{-1}\left(\mathrm{r}^{2}=0.999\right)$ for DPPH obtained on the kinetic analysis compares with values reported by others authors [9]. Using this coefficient DPPH scavenging could be expressed as concentration $\left(\mu \mathrm{molL}^{-1}\right)$. Antioxidant kinetics of ascorbic acid showed a single phase DPPH scavenging (Fig. 1a). Ascorbic acid kinetics reduces the DPPH concentration at the beginning of the reaction in a concentrationdependent manner. Moreover, no change on
DPPH concentration appeared at prolonged kinetic time evaluation. The slope of DPPH and ascorbic acid correlation plot disclose a stoichiometric constant $(\sigma)$ of 1.17 (Fig. 1b).

The antioxidant activity of methanolic extracts from wild plants of southern Sonora especially Krameria erecta showed biphasic kinetics. The first phase illustrates fast kinetics on DPPH concentration decay at the beginning of reaction, followed by a slower kinetics with a gradual reduction of DPPH concentration (Fig 2a). Other plants exhibited similar kinetics with amplitude values proportional to antioxidant activity. The slope of DPPH and Krameria erecta extract correlation plot describes the stoichiometric constant for fast and slow phase with high-quality correlation $\left(r^{2}=0.99\right)$ and individual phase stoichiometric match with total stoichiometric constant (Figure 2b).

Ascorbic acid stoichiometric constant functioned as control to assess antiradical activity of each plant sample (Table 1). These results demonstrate that Rhizophora mangle and Krameria erecta exhibited the highest anti radical-activity among the five plants evaluated.

\section{Phytochemical screening}

The performance of phytochemical screening on methanol extract allows kinetic results correlation with specific organic compounds groups (Table 2). The results show that most samples yield positive to polyphenols and terpenes tests. Moreover, Rhizophora mangle and Krameria erecta showed a similar phytochemical profile and consistent with kinetic results indicating presence of flavonoids. The phytochemical screening results of plant extracts aided in establishing the compounds analyzed in the HPLC method. The antioxidant compounds in the extracts suggested by our kinetic analysis have been identified in other plants with antioxidant capacity $[6,10,11]$.

\section{Phenolic compounds}

The Rhizophora mangle and Krameria erecta plants present the highest antioxidant activity among plants reported in this study. In this sense, the phenolic compounds detected in plant methanolic extracts were gallic acid, caffeic acid, ferulic acid, vanillic acid, protocatechuic acid, chlorogenic acid and benzoic acid (Table 3). 

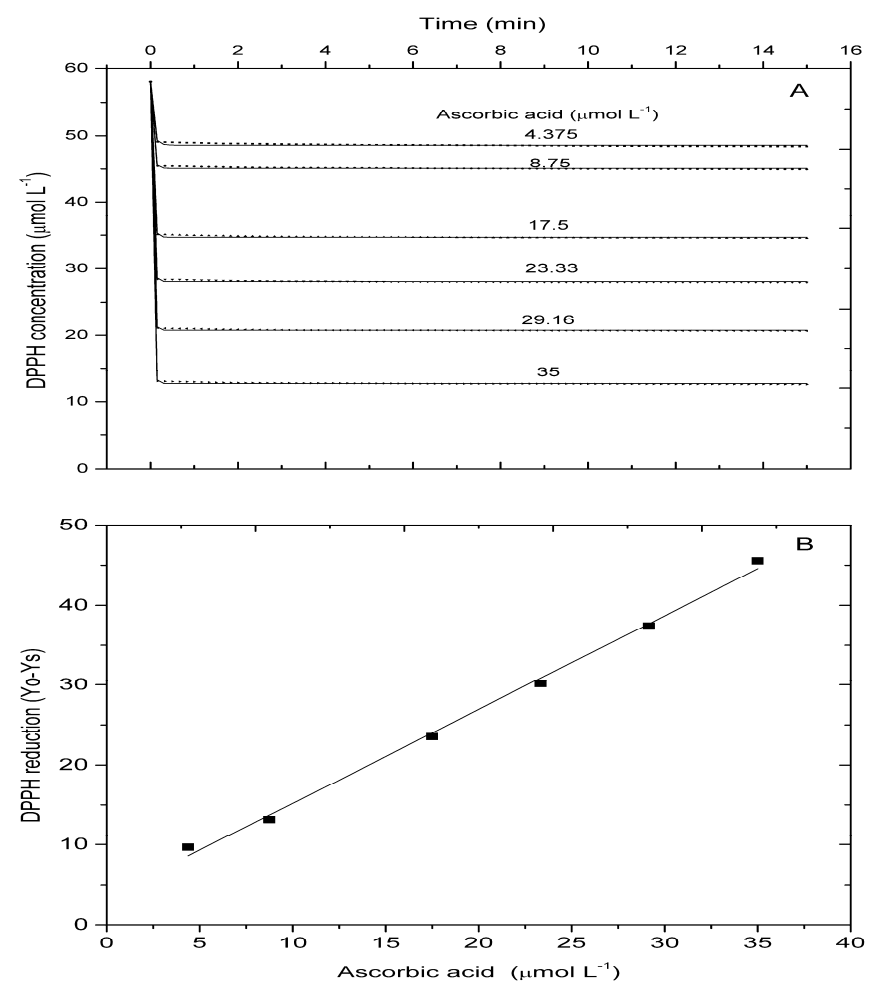

Figure 1: Kinetics of Ascorbic acid antioxidant activity (A) DPPH radical reduction $\left(58 \mu \mathrm{molL}^{-1}\right)$ by ascorbic acid at distinct concentrations $(\mu \mathrm{M})$. (B) Graphic representation of DPPH reduction (Yo-Ys) at each ascorbic acid concentration
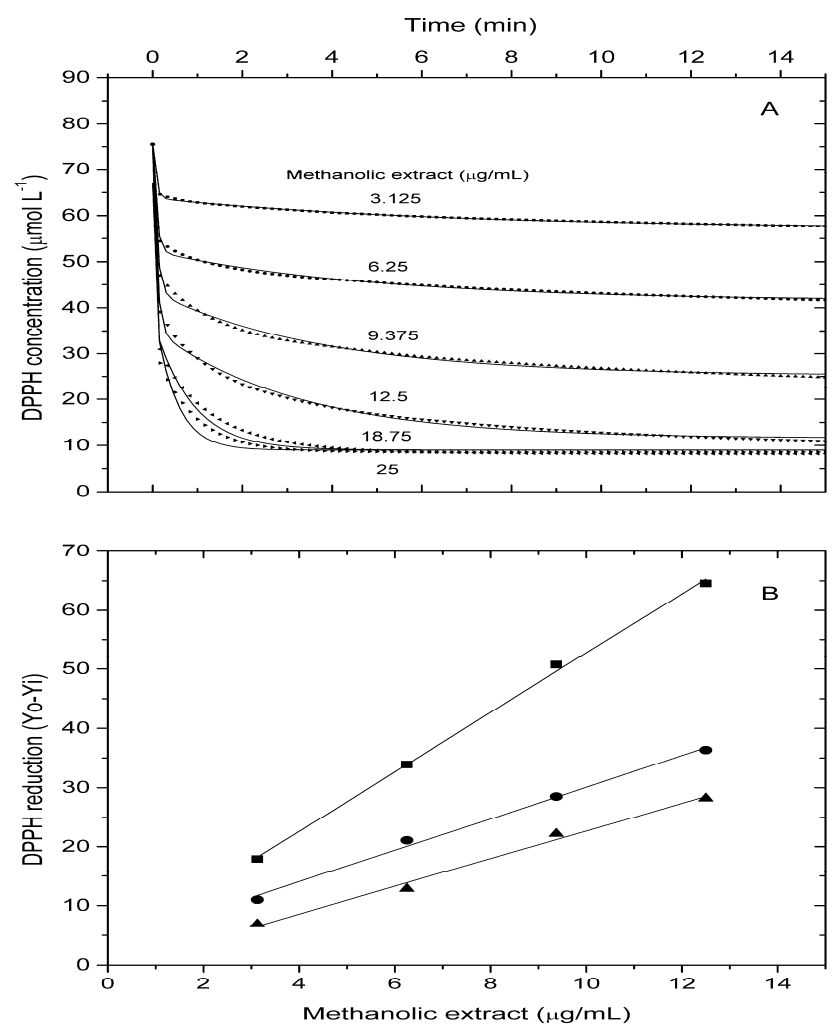

Figure 2: Kinetics of Krameria erecta antioxidant activity. (a) DPPH radical reduction $\left(75 \mu \mathrm{molL}^{-1}\right)$ by $\mathrm{Krameria}$ erecta at distinct concentrations $(\mu \mathrm{g} / \mathrm{mL})$. (b) Graphic representation of DPPH reduction (Yo-Ys) at each Krameria erecta concentration. Fast phase kinetics $(\bullet \bullet)$, slow phase kinetics $(\boldsymbol{\Delta})$ and total kinetics $(\boldsymbol{\bullet})$ 
Table 1: Stoichiometric constants of methanolic extract from medicinal plants of southern Sonora, Mexico

\begin{tabular}{lllllll}
\hline \multirow{2}{*}{ Plant } & \multicolumn{3}{l}{ Stoichiometric constant } & \multicolumn{3}{l}{$\begin{array}{l}\text { Antiradical activity } \boldsymbol{~} \boldsymbol{\mu m o l L}^{-1} \\
\text { equivalents of ascorbic acid) }\end{array}$} \\
\cline { 2 - 8 } & $\mathbf{m s}$ & $\mathbf{m 1}$ & $\mathbf{m} 2$ & $\mathbf{A}_{\mathbf{t}}$ & $\mathbf{A}_{\mathbf{1}}$ & $\mathbf{A}_{\mathbf{2}}$ \\
\hline Rhizophora mangle & 5.26 & 3.05 & 2.21 & 13.487 & 7.821 & 5.667 \\
Krameria erecta & 5.02 & 2.67 & 2.34 & 12.872 & 6.846 & 6.000 \\
Lycium berlandier & 0.643 & 0.39 & 0.252 & 1.649 & 1.000 & 0.646 \\
Vallesia glabra & 0.379 & 0.245 & 0.133 & 0.972 & 0.628 & 0.341 \\
Forchhammeria watsonii & 0.225 & 0.124 & 0.1 & 0.577 & 0.318 & 0.256 \\
\hline
\end{tabular}

Table 2: Phytochemical profile of methanol extracts of medicinal plants of southern Sonora, Mexico

\begin{tabular}{|c|c|c|c|c|c|}
\hline $\begin{array}{l}\text { Phytochemical } \\
\text { test }\end{array}$ & $\begin{array}{c}\text { Rhizophora } \\
\text { mangle }\end{array}$ & $\begin{array}{c}\text { Krameria } \\
\text { erecta }\end{array}$ & $\begin{array}{l}\text { Forchammeria } \\
\text { watsonii Rose }\end{array}$ & $\begin{array}{c}\text { Lycium } \\
\text { berlandieri }\end{array}$ & $\begin{array}{c}\text { Vallesia } \\
\text { glabra }\end{array}$ \\
\hline Alkaloids & - & - & - & - & + \\
\hline Polyphenols & + & + & - & + & + \\
\hline Terpenes & + & + & + & + & + \\
\hline $\begin{array}{l}\text { Sesquiterpene- } \\
\text { lactones }\end{array}$ & + & + & - & + & - \\
\hline Gelatin-tannin & + & + & - & + & + \\
\hline Flavonoids & + & + & + & - & - \\
\hline Liebermann & - & - & - & - & + \\
\hline Saponins & + & - & + & - & - \\
\hline
\end{tabular}

Table 3: Phenolic compound concentrations of Krameria erecta and Rhizophora mangle

\begin{tabular}{lll}
\hline \multirow{2}{*}{ Phenolic compound } & Krameria erecta & Rhizophora mangle \\
\cline { 2 - 3 } & \multicolumn{1}{c}{ Concentration $(\mathbf{m g} / \mathbf{g}$ of methanol extract $\mathbf{S} \mathbf{S D})$} \\
\hline Gallic acid & $0.0086 \pm 0.0003$ & $0.00285 \pm 7.75 \times 10^{-5}$ \\
Caffeic acid & $0.012 \pm 0.0005$ & $0.035 \pm 0.0007$ \\
Chlorogenic acid & $0.310 \pm 0.014$ & $0.151 \pm 0.0071$ \\
Vanillic acid & $22.29 \pm 0.7238$ & $7.13 \pm 0.125$ \\
Benzoic acid & $0.148 \pm 0.006$ & $0.011 \pm 0.0004$ \\
Ferulic acid & $619.92 \pm 28.165$ & $688.45 \pm 18.21$ \\
Protocatechuic acid & $1.40 \pm 0.077$ & $0.360 \pm 0.020$ \\
\hline
\end{tabular}

\section{DISCUSSION}

Rhizophora mangle presented a DPPH scavenging of $43 \%$ using $12.5 \mu \mathrm{g} / \mathrm{mL}$ extract concentration. This result is consistent with an earlier report on Rhizophora mangle from the region of Caimito Beach (Havana, Cuba) [12]. Recently, a DPPH radical scavenging activity in Krameria erecta from north-west Mexico was reported with values of $92.74 \%$ [13]. This result is consistent with the DPPH scavenging values obtained in this work.

The stoichiometric constant is a crucial parameter for antioxidant activity because it describes the number of radical molecules that are stabilized from each antioxidant molecule. Rhizophora mangle presents higher values in the fast phase (m1) contrasting slow phase (m2). This pattern implicates that antioxidant compounds are capable of radical stabilization by fast hydrogen transfer. In the other hand, Krameria erecta had similar stoichiometric values in fast and slow phases, suggesting that hydrogen displacement occurs by fast or slow mechanism in equal proportion. This behavior is distinctive from free or mono-substituted catechol antioxidant compounds.

The results were put side by side with stoichiometric constant values of purified antioxidant compounds [6,14]. This analysis suggest that polyphenols as such as gallic acid, epigallocatechin, chlorogenic acid and quercetin are responsible for total antioxidant capacity in Rhizophora mangle and Krameria erecta $(\mathrm{m}=$ 5.26, 5.02, respectively). These results agree with those reported for Rhizophora mangle collected from Camaguey (Cuba) which indicated its main composition as epicatechin (8.44\%), catechin $(6.60 \%)$ and chlorogenic acid $(2.15 \%)$ [15]. 
Ferulic and vanillic acid represent the main phenolic acids in Rhizophora mangle and Krameria erecta samples. These phenolic compounds contribute to antioxidant activity due to the arrangement of functional groups (hydroxyl) about its nuclear structure for hydrogen donation in order to stabilize radical molecules [16].

The lowest phenolic concentration values in the Rhizophora mangle and Krameria erecta samples correspond to gallic, caffeic, chlorogenic, benzoic and protocatechuic acids. These concentrations are below the range of 10 to $30 \mathrm{mg} / \mathrm{g}$ reported for others medicinal plants with antioxidant properties $[17,18]$. However, compared with usual vegetables and fruits (dietary plants) as banana (gallic acid 0.003 $\mathrm{mg} / \mathrm{g}$ ), apple (chlorogenic acid $0.0176 \mathrm{mg} / \mathrm{g}$ ), blueberry (gallic acid $0.0048 \mathrm{mg} / \mathrm{g}$; caffeic acid $0.0216 \mathrm{mg} / \mathrm{g}$ ), cherry tomato (gallic acid 0.0088 $\mathrm{mg} / \mathrm{g}$ ) and citrus (caffeic acid $0.0085 \mathrm{mg} / \mathrm{g}$; chlorogenic acid $0.0054 \mathrm{mg} / \mathrm{g}$ ); Rhizophora mangle and Krameria erecta possess 7 fold higher concentrations of these phenolic acids [19].

Vanillic acid content on Rhizophora mangle and Krameria erecta is 300 and 800 fold higher than other antioxidant plants. The vanillic acid concentrations in other plants have distinct values: Capparis spinosa $(0.048 \mathrm{mg} / \mathrm{g})$, Geranium purpureum $(0.02 \mathrm{mg} / \mathrm{g})$, Phytolacca americana $(0.039 \mathrm{mg} / \mathrm{g})$ and Styrax officinalis $(0.011 \mathrm{mg} / \mathrm{g})$ [11]. The ferulic acid accumulation on both samples is at least 500 fold higher than those reported for other plants used on ethnopharmacology [20]. In addition, ferulic acid concentration on Rhizophora mangle and Krameria erecta is $10^{4}$ fold higher compared with antioxidant fruits as papaya $(0.0081 \mathrm{mg} / \mathrm{g})$ and orange $(0.0045 \mathrm{mg} / \mathrm{g})$ [19]. Ferulic acid has implications on antihyperglycaemic and antioxidant properties decreasing lipid peroxidation and enhancing glutathione and antioxidant enzymes, reducing the severity of diabetes [21]. The data obtained on this work supports the beneficial properties attributed to medicinal plants in folk medicine.

\section{CONCLUSION}

Southern Sonora plants, namely, Rhizophora mangle and Krameria erecta, possess five times the antioxidant capacity of ascorbic acid, indicating that Sonora plants are a good source of bioactive compounds for study and application. In addition, most of the antioxidant studies in plant samples are limited to antioxidant capacity reports in terms of percent of radical stabilization, but lack discussion of the antioxidant activity responsible compounds. In this work, we show that kinetic analysis implementation supports prediction of metabolites responsible for antioxidant activity and facilitate the experimental design of specific assays for active compound isolation. Finally, the high antioxidant activity and bioactive compounds profile identified on Sonora plants support the beneficial properties attributed to these plants in traditional medicine, and contribute to a better understanding of alternative medicine.

\section{ACKNOWLEDGEMENT}

JA Rosas-Rodríguez is grateful for support from "Apoyos Complementarios para la Consolidación Institucional de Grupos de Investigación: Retención 149021" awarded by Mexico's National Council for Science and Technology (CONACYT). The authors are grateful to "Dirección de Investigación y Posgrado" of Universidad de Sonora for financial support (Project: URS12-06).

\section{REFERENCES}

1. Mohammed A-R, Tarpley L. Impact of high nighttime temperature on respiration, membrane stability, antioxidant capacity, and yield of rice plants. Crop Sci 2009; 49: 313-322.

2. Barrón-Yánez RM, García-Mateos M, Soto-Hernández MR, Colinas-León T, Kite G. Flavonoides y actividad antioxidante de Calia secundiflora (Ort.) Yakovlev. Rev Fitotec Mex 2011; 34: 151-157.

3. Bautista-Cruz A, Arnaud-Viñas MR, Martínez-Gutiérrez GA, Sánchez-Medina PS, Pérez-Pacheco R. The traditional medicinal and food uses of four plants in Oaxaca, Mexico. J Med Plants Res 2011; 5: 34043411.

4. Sendra JM, Sentandreu E, Navarro JL. Reduction kinetics of the free stable radical 2, 2-diphenyl-1picrylhydrazyl $(D P P H \cdot)$ for determination of the antiradical activity of citrus juices. Eur Food Res Technol 2006; 223: 615-624.

5. Molyneux $P$. The use of the stable free radical diphenylpicrylhydrazyl (DPPH) for estimating antioxidant activity. Songklanakarin J Sci Technol 2004; 26: 211-219.

6. Goupy P, Dufour C, Loonis M, Dangles O. Quantitative kinetic analysis of hydrogen transfer reactions from dietary polyphenols to the DPPH radical. J Agr Food Chem 2003; 51: 615-622.

Trop J Pharm Res, September 2014; 13(9): 1492 
7. Jones WP, Kinghorn $A D$. 2005. Extraction of plant secondary metabolites. Pages 323-351. Natural products isolation, Springer.

8. Harbaum B, Hubbermann EM, Wolff C, Herges R, Zhu Z, Schwarz $K$. Identification of flavonoids and hydroxycinnamic acids in pak choi varieties (Brassica campestris L. ssp. chinensis var. communis) by HPLC-ESI-MSn and NMR and their quantification by HPLC-DAD. J Agr Food Chem 2007; 55: 8251-8260.

9. Bondet $V$, Brand-Williams W, Berset C. Kinetics and Mechanisms of Antioxidant Activity using the DPPH. Free Radical Method. Food Sci Technol-LEB 1997; 30: 609-615.

10. Dahanukar S, Kulkarni R, Rege N. Pharmacology of medicinal plants and natural products. Indian $J$ Pharmacol 2000; 32: S81-S118.

11. Proestos C, Boziaris I, Nychas G-J, Komaitis M. Analysis of flavonoids and phenolic acids in Greek aromatic plants: Investigation of their antioxidant capacity and antimicrobial activity. Food Chem 2006; 95: 664-671.

12. Sánchez JC, García RF, Cors MTM. 1, 1-Diphenyl-2picrylhydrazyl radical and superoxide anion scavenging activity of Rhizophora mangle (L.) bark. Phcog Res 2010; 2: 279.

13. Jiménez-Estrada M, Velázquez-Contreras C, GaribayEscobar A, Sierras-Canchola D, Lapizco-Vázquez R, Ortiz-Sandoval C, Burgos-Hernández A, RoblesZepeda RE. In vitro antioxidant and antiproliferative activities of plants of the ethnopharmacopeia from northwest of Mexico. BMC Complem Altern M 2013; 13: 12 .
14. Villano $D$, Fernández-Pachón $M$, Moyá $M$, Troncoso $A$, García-Parrilla M. Radical scavenging ability of polyphenolic compounds towards DPPH free radical. Talanta 2007; 71: 230-235.

15. Sánchez PL, Varcalcel L, Escobar A, Noa M. Polyphenol and phytosterol composition in an antibacterial extract from Rhizophora mangle L. bark. J Herb Pharm 2007; 7: 107.

16. Soobrattee MA, Neergheen VS, Luximon-Ramma $A$, Aruoma Ol, Bahorun T. Phenolics as potential antioxidant therapeutic agents: mechanism and actions. Mut Res-Fund Mol M 2005; 579: 200-213.

17. Cai $Y$, Luo $Q$, Sun $M$, Corke H. Antioxidant activity and phenolic compounds of 112 traditional Chinese medicinal plants associated with anticancer. Life Sci 2004; 74: 2157-2184.

18. Shan B, Cai YZ, Sun M, Corke H. Antioxidant capacity of 26 spice extracts and characterization of their phenolic constituents. J Agr Food Chem 2005; 53: 7749-7759.

19. Li F, Bo-Tao X, Xiang-Rong X, Ren-You G, Yuan Z, EnQin X, Hua-Bin L. Antioxidant capacities and total phenolic contents of 62 fruits. Food Chem 2011; 129: 345-350.

20. Proestos C, Chorianopoulos N, Nychas G-J, Komaitis M. RP-HPLC analysis of the phenolic compounds of plant extracts. Investigation of their antioxidant capacity and antimicrobial activity. J Agr Food Chem 2005; 53: 1190-1195.

21. Balasubashini M, Rukkumani R, Viswanathan $P$, Menon $V P$. Ferulic acid alleviates lipid peroxidation in diabetic rats. Phytother Res 2004; 18: 310-314. 